\title{
TRABALHO E EDUCAÇÃO: UM OLHAR SOCIOLÓGICO
}

\section{Edson Caetano}

\section{RESUMO}

Este artigo faz uma reflexão sobre o binômio educação e trabalho, tendo como referência a estratégia de reestruturação do processo produtivo e os programas educacionais implementados no setor da construção. O processo de reestruturação produtiva no setor se inicia em 1983, onde as construtoras foram compelidas a promover alterações na organização do processo de trabalho. É dentro deste cenário que se inserem tanto a estratégia da terceirização, como a alfabetização/qualificação profissional. Portanto, nosso foco de análise incidiu sobre estes dois tipos distintos de iniciativas, que correspondem a dois momentos diferentes na história recente da empresa pesquisada. Para tanto procuramos compreender as mudanças e as implicações nas condições de trabalho, na organização e no conteúdo do trabalho decorrentes da adoção da terceirização. Esta análise se ocupou também dos projetos de alfabetização mantidos nos canteiros de obras, através do confronto entre a visão expressa pelo setor administrativo da construtora pesquisada e pelos trabalhadores acerca do significado, da importância e do papel atribuído à educação.

\section{PALAVRAS-CHAVE}

Educação e trabalho; Alfabetização de adultos; Reestruturação produtiva; Terceirização

\section{WORK AND EDUCTION: ASOCIOLOGICAL VIEW}

\begin{abstract}
This article is a reflection on the binomial education and work, with reference to the strategy of restructuring the production process and educational programs implemented in the construction sector. The process of restructuring the productive sector is to begin in 1983, where the builders were compelled to promote changes in the organization of the work process. It is within this scenario that would fit both the strategy of outsourcing, such as literacy / professional qualification. So our focus of analysis focused on these two distinct types of initiatives, which correspond to two different times in the recent history of the company searched. For in such a way we look for to understand the changes and the implications in the conditions of work, the organization and the decurrently content of the work of the adoption of the outsourcing. This analysis is also occupied the projects of literacy kept billowing in the works, through the confrontation between the vision expressed by the construction sector's administrative and searched by employees about the meaning, importance and role of education.
\end{abstract}

\section{KEYWORDS}

Education and labor; The adult literacy, Production restructuring; Outsourcing 


\section{INTRODUÇÃO}

Este trabalho analisa as implicações da terceirização adotada por um número crescente de empresas de edificações habitacionais, visando o aumento da competitividade. Analisa também os significados da alfabetização para o capital e o trabalhador.

Diante da crise que assolou este subsetor a partir de 1983, as empresas de edificações foram compelidas a promover alterações na organização do processo de trabalho, quer pelo colapso do Sistema Financeiro da Habitação, quer pelas novas exigências do mercado consumidor associadas à pressão dos operários da construção.

É dentro deste cenário de instabilidade e de busca por um novo modelo de processo de trabalho, que se inserem tanto a estratégia da terceirização, como a alfabetização e a qualificação profissional. Portanto, nosso foco de análise incidirá sobre estes dois tipos distintos de iniciativas, que correspondem a dois momentos diferentes na história recente da empresa pesquisada.

\section{PROCEDIMENTOS METODOLÓGICOS}

O estudo empírico baseou-se na análise de uma importante construtora brasileira e de suas empresas terceirizadas. Os critérios para a escolha desta construtora foram: a sua importância no cenário da construção habitacional e a constatação de que em sua história recente foram implementadas experiências de alfabetização e de terceirização, possibilitando, assim, vislumbrar duas estratégias distintas numa mesma empresa.

Na construtora pesquisada, realizamos entrevistas com representantes da gerência e com trabalhadores de dois canteiros de obras. A partir da análise dos dados obtidos através dos depoimentos, foi possível compreendermos a intensidade da precariedade que acompanha a terceirização e concluímos por outro lado, que a educação é um dos instrumentos capazes de promover a inserção no mercado de trabalho de um enorme contingente de marginalizados em nossa sociedade. 


\section{A CONSTRUÇÃO DE EDIFICAÇÕES HABITACIONAIS E DE ESPAÇOS EDUCACIONAIS}

Em 1987 a empresa pesquisada criou o 'Projeto Educar para o Amanhã' destinado à alfabetização dos trabalhadores por ela mantidos nos canteiros de obras.

O momento de criação do programa de alfabetização é marcado, segundo Barone e Letelier (1995), pela retração da migração para os grandes centros urbanos e, por conseguinte, uma queda na oferta de força de trabalho. Em tal conjuntura, as empresas de edificações são compelidas a disputar trabalhadores com setores produtivos que oferecem melhores condições de trabalho.

Do ponto de vista conjuntural, o momento de criação dos projetos de alfabetização é marcado pela articulação entre a crise econômica e a crescente exigência do mercado consumidor do produto moradia. Para garantir maior competitividade, as empresas de edificações intensificam esforços visando "o aumento da produtividade, a diminuição do desperdício de materiais, a diminuição dos acidentes de trabalho e a melhoria na qualidade do produto" (BARONE; LETELIER, 1995, p. 447).

A alfabetização, segundo a empresa pesquisada, cumpre um papel essencialmente instrumental por ser concebida como um instrumento capaz de garantir o incremento da produtividade e, portanto, da lucratividade.

"A empresa tinha uma vontade grande de que a questão da qualidade fosse trabalhada a partir da oportunidade da escola. Quer dizer, que o trabalhador tivesse crítica em cima daquele trabalho que ele estava fazendo, então a escola foi um investimento da empresa nesse sentido, na busca dessa qualidade” (Sandra, psicóloga)

Outro aspecto viabilizado através da educação e extremamente valorizado, segundo a construtora, é o suposto aumento da responsabilidade que o trabalhador alfabetizado demonstra ter durante a execução de seu respectivo ofício:

"Com a alfabetização, o cara passa saber que se ele faltar vai acarretar mais trabalho para o outro. Ele passa a pensar um pouco mais em grupo, ele tem uma consciência a nível de acidentes, ele tem uma consciência a nível de desperdício, retrabalho." (Ana Luiza, responsável pelo Projeto Educar) 
Cumpre destacar que as condições encontradas pelos trabalhadores diariamente nos canteiros de obras, em sua grande maioria, não apresentam alterações importantes, permanecendo assim, um local de trabalho marcado pela sujeira, desorganização, barulho, perigo etc.. Isso equivale a dizer que o trabalhador modificou-se qualitativamente a partir da alfabetização, principalmente pelo resgate de sua auto-estima; mas o canteiro de obras não, permanecendo então um descompasso entre o perfil do trabalhador e do local de trabalho.

Ainda em relação à valorização do processo de escolarização detectado nas falas de parte da gerência dos canteiros de obras, é enfatizado o papel desempenhado pelo sistema educacional com referência ao adestramento, no sentido de moldar o trabalhador segundo os padrões desejados pelo capital (FRIGOTTO, 1999).

"O principal da escola é dar consciência e disciplina ao operário. A primeira coisa é que ele tem que ser disciplinado, não pode ser bocudo, respondão, tem que ser uma pessoa fácil de lidar. Tudo que você manda ele fazer, ele está pronto para fazer.” (Orlando, mestre de obras, grifos nossos)

Mesmo que parte da gerência dos canteiros de obras mantidos pela empresa pesquisada pense a educação como um meio de adestrar o trabalhador, isto não implica que a escola cumpra efetivamente este papel. Este descompasso entre o papel que o capital deseja que a escola cumpra e a realidade na sala de aula explica-se, como bem assinalam Carnoy e Levin (1993, p. 70), por ser a educação "ao mesmo tempo, o resultado de contradições e origem de novas contradições. É uma área de conflitos a respeito da produção de conhecimentos, ideologia e emprego (...)".

"A escola deve transformar esse trabalhador num cidadão. Então é isso que eu chamo ser cidadão: é a pessoa ouvir, tentar criticar, emitir a sua opinião, coisa que eles não fazem.” (Ana Luiza, responsável pelo Projeto Educar)

O depoimento acima expressa a incapacidade que a construtora possui em controlar não somente os conteúdos e a postura dos professores, mas sobretudo, a dinâmica das aulas. Dito de outra maneira, o dia-a-dia escolar é construído/reconstruído pelos atores envolvidos no processo de aprendizagem (professor, aluno) e inexiste planejamento/intervenção pedagógica capaz de prever e ou controlar totalmente o inesperado característico da sala de aula. 


\section{ALFABETIZAÇÃO NOS CANTEIROS DE OBRAS: POSSÍVEIS SIGNIFICADOS}

Os trabalhadores/alunos que passaram e passam pelos canteiros/escolas procurando aprender a ler e escrever apresentam em comum não só a origem rural, principalmente da região norte e nordeste, mas principalmente um semblante cansado de quem teve uma história de vida pautada pela pobreza e um cotidiano de trabalho extremamente penoso.

“Eu trabalhava na lavoura na Bahia junto com a minha mãe porque o meu pai, antes de eu nascer, ele morreu. Aí, fiquei eu com a minha mãe e meus dois avôs. Nisso, eu comecei a estudar, acho que eu estudei uns seis meses, aí já comecei a trabalhar porque eu já tinha uma forcinha e nós tudo era pobrezinho. Aí, larguei a escola para trabalhar para ajudar minha família”. (Francisco, faxineiro)

A totalidade dos trabalhadores que participaram do 'Projeto Educar' são homens com idade entre 18 e 50 anos, analfabetos ou semi-analfabetos, moradores da periferia de São Paulo, trabalhadores sem qualificação anterior e que obtiveram na construção civil a única oportunidade de emprego em São Paulo.

A partir do instante em que se consegue visualizar a penúria que marca a existência destes trabalhadores, causa-nos espanto o fato deles ainda terem força/disposição para estudar ao final da jornada de trabalho.

"O que mata na construção é a canseira. A gente tem que gostar mesmo de estudar, tem que ter vontade porque geralmente no serviço de obras chega a tarde, o cara ta num bagaço danado: é frio, é chuva, é sol, é vento, tudo isso na cabeça da gente o dia todo, não tem como fugir não.” (Francisco, pedreiro)

As dificuldades enfrentadas diariamente por estes trabalhadores decorrem de várias situações. Em primeiro lugar, a maioria deles acorda três horas antes do início da jornada de trabalho e retorna as suas casas no final do dia, entre três e quatro horas após o final das aulas ${ }^{1}$. Em segundo lugar, diferentemente de outros setores produtivos, o subsetor de edificações habitacionais exige que o trabalhador execute seu respectivo ofício sob as intempéries do tempo. Por último, e não menos importante, é o traço característico do trabalho

\footnotetext{
1 É interessante ressaltar que de tempos em tempos o trabalhador desloca-se para um canteiro de obras numa região diferente, implicando um interminável acostumar-se à itinerários diferentes e, por conseguinte, ônibus, trens, metrôs com horários diferenciados.
} 
no canteiro de obras em que o trabalho concretiza-se através do dispêndio da força física do trabalhador.

Apesar do cansaço, do desânimo, da falta de perspectivas, estes trabalhadores, muitos com idade acima dos 50 anos, superam-se e procuram habituar-se ao manuseio de um instrumento que não requer força, mas sim habilidade. Este instrumento é o lápis. Nas duas horas de escola, a força física não se faz necessária e quando os observamos sentados tentando desenhar as primeiras letras, quase que não enxergamos trabalhadores fortes e calejados, mas sim crianças tentando, errando e, por fim, com o olhar brilhante, conseguindo escrever alguma palavra.

A leitura aparece para os alunos do projeto como algo que alterou qualitativamente as suas vidas não só no âmbito do trabalho, mas também no cotidiano. A maior parte dos trabalhadores valoriza a leitura face aos benefícios alcançados no âmbito da vida cotidiana, tal como a leitura de jornal, da carta da família, do letreiro do ônibus e metrô etc.

"Aqui eu aprendi a ler um pouco, agora eu não tenho mais dúvida em ir em tal lugar porque eu já sei ler o nome de ônibus, estação de metrô. Para onde eu for agora eu não fico mais perguntando a ninguém porque a gora eu vou sozinho." (José Carlos, marceneiro)

O domínio da leitura possibilita ao trabalhador locomover-se através do ônibus e metrô sem o constrangimento de ter que perguntar às pessoas. Com isso, o grau de autonomia e liberdade do trabalhador aumenta e consequentemente a sua auto-estima, pois pior que ser analfabeto é explicitar diariamente tal condição a desconhecidos.

Outra maneira do trabalhador sentir-se inserido no mundo baseado nos códigos escritos e que se relaciona à sua auto-estima é o ler e portar o jornal. Uma grande parte dos trabalhadores chega à obra para iniciar a jornada de trabalho com um jornal embaixo do braço e isso, por si só, separa aqueles que sabem ler dos que são analfabetos.

"O mais importante para mim é saber ler, a minha irmã sempre compra jornal então eu posso pegar, posso ler algumas coisas no jornal que nem negócio de esportes que eu gosto demais." (Orlando, ajudante) 
Nos depoimentos, percebe-se que a importância atribuída à leitura é superior àquela atribuída ao domínio da escrita. A esse respeito, Barone e Letelier (1995, p.465) salientam que, "no viver cotidiano, em geral, as necessidades de leitura sobrepõem-se às necessidades de escrita - isto faz com que as referências dos trabalhadores direcionem-se, com maior freqüência, à primeira destas habilidades".

Os conhecimentos obtidos através da escolarização são considerados importantes em várias situações da vida do trabalhador, porém, o mesmo não ocorre em relação à execução do trabalho no canteiro de obras, porque não modifica o conteúdo do trabalho e as relações de poder no canteiro.

"A gente não saber ler e escrever na parte de pedreiro não atrapalha porque o pedreiro não precisa ter muito estudo. A parte de cálculo, essas coisa aí já é para o engenheiro, mestre de obras, quer dizer, isso aí nem para o encarregado já não faz tanta falta." (Paulo, pedreiro de alvenaria)

A totalidade dos depoimentos obtidos junto aos trabalhadores dos canteiros de obras expressa a inexistência de vínculo entre escolarização e execução das tarefas, independentemente do ofício, ou seja, a execução correta do trabalho não requer um trabalhador com determinado nível educacional, mas sim que o mesmo possua experiência profissional adquirida no próprio local de trabalho.

Para os trabalhadores entrevistados, a escolarização é tida como o único instrumento capaz de concretizar o sonho de sair do canteiro de obras e trabalhar num outro setor produtivo, com melhores condições de trabalho.

"Se eu tivesse estudado, poderia ter um serviço melhor, eu jamais ia querer trabalhar aqui e é claro que eu quero sair. É aquilo que eu falo: hoje em dia o estudo não é tudo, mas a maior arma minha e eu acho que para o pobre é um estudo." (Nelson, ajudante, 1999)

O desemprego passa a ser compreendido pelo trabalhador que passou pela escola como um fenômeno que independe da vontade do trabalhador; desta maneira, a escola estimula a criticidade no aluno/trabalhador, fornecendo-lhe ferramentas que lhe possibilite compreender o mundo em que vive ${ }^{2}$.

\footnotetext{
${ }^{2}$ Enguita (1989, p. 218) entende que "embora possamos caracterizar a escola, em geral, como uma instituição que busca moldar as pessoas, não é possível ignorar que estas não são simples matérias primas ou produtos
} 
"É óbvio que o estudo me ajuda e vai me ajudar mesmo se eu tiver desempregado. Mesmo assim, ele vai tá me ajudando porque pelo menos eu vou ter a certeza que eu estou procurando serviço não por causa de mim, mas pela situação do país." (Marcos, ajudante)

No depoimento precedente, a importância da escolarização não está na possível superação do desemprego, mas sim na compreensão da problemática do desemprego enquanto um problema social e não individual.

Em 1988, a construtora pesquisada inesperadamente desativou o 'Projeto Educar para o Amanhã'. O sentimento dos trabalhadores expressa desalento e inconformismo. Desalento no sentido de não conseguir continuar os estudos em outro local fora do canteiro de obras e inconformismo pela ausência de justificativas por parte da empresa.

“Tá com um ano e pouco que a escola parou e não voltou mais. Falaram que ia voltar, mas até hoje nada. O pessoal tem reclamado, o pessoal que estudava gostava porque essa oportunidade que eles deram aqui eles não têm lá fora. (Domingos, auxiliar de almoxarifado)”

A partir da análise dos depoimentos fornecidos pelos trabalhadores acerca da importância da escola em suas vidas, concluímos que a alfabetização significou para esses trabalhadores reforço à auto-estima, melhor convívio no local de trabalho, o domínio do código escrito e, fundamentalmente, a criticidade e a cidadania que lhes possibilita o sentimento de pertencimento a uma dada sociedade.

Na perspectiva da construtora pesquisada, a educação é uma ferramenta capaz de melhorar o desempenho do trabalhador durante a execução de seus ofícios. A alfabetização emerge também como necessidade de adequar o nível escolar a novos processos construtivos, que demandam um trabalhador capaz de ler manuais de procedimento.

Para o trabalhador, a escolarização não tem relação direta com a execução do trabalho nos canteiros de obras, pois os segredos dos ofícios são aprendidos através da observação junto ao oficial e demandam prática e não leitura ou escrita

semitransformados dos quais se pode fazer qualquer coisa, como sugere a metáfora da tábula rasa. Trata-se, pelo contrário de seres humanos, dotados de inteligência e vontade, cujos desejos, preferências, aversões, expectativas, experiências, etc., se traduzem em respostas individuais e grupais aos imperativos da instituição, com o resultado final de que os resultados obtidos por esta não podem chegar jamais a coincidir com seus desígnios iniciais". 


\section{A EMPRESA ESTUDADA NO CONTEXTO DA TERCEIRIZAÇÃO}

Nos últimos trinta anos, principalmente nas décadas de 80 e 90, intensifica-se o processo denominado 'reestruturação produtiva', visto que a articulação entre o aumento da produtividade e a redução de custos é considerada a alternativa à subsistência das empresas num cenário doravante marcado pelo acirramento da concorrência entre as mesmas. A concorrência que até então permanecia, em certa medida, circunscrita aos mercados nacionais, não mais observará as fronteiras regionais, ou seja, a produção, a distribuição e o consumo de bens mundializam-se ${ }^{4}$.

A partir de 1996, diante de um mercado extremamente competitivo, concorrencial e diversificado, a construtora pesquisada optou pela terceirização enquanto estratégia para ampliar a sua eficiência e assegurar a sua própria sobrevivência.

Em 1999, a empresa havia terceirizado todas as etapas do processo construtivo no segmento de edificações habitacionais (através da padronização e estandardização do projeto) e nos demais segmentos este índice atinge 90\% das etapas.

A terceirização e as inovações tecnológicas evidenciam um cenário marcado pela crescente precarização das condições de trabalho. A referida degradação das condições de trabalho pressupõe a flexibilização progressiva do mercado de trabalho através das seguintes iniciativas:

\footnotetext{
3 “A reestruturação produtiva e industrial consiste em um processo que compatibiliza mudanças institucionais e organizacionais nas relações de produção e de trabalho, bem como redefinição de papéis dos estados nacionais e das instituições financeiras, visando a atender às necessidades de garantia de lucratividade”. (CATTANI, 1997, p. 202).

4 “O termo de origem francesa ‘mundialização' (mondialisation) encontrou dificuldades para se impor, não apenas em organizações internacionais, mesmo que supostamente bilíngües, como a OCDE, mas também no discurso econômico e político francês. Isso deve-se, claro, ao fato de que o inglês é o veículo linguístico por excelência do capitalismo e que os altos executivos dos grupos franceses estão entupidos dos conceitos e do vocabulário em voga nas business schools. Mas também, com certeza, ao fato de que o termo 'mundialização' tem o defeito de diminuir, pelo menos um pouco, a falta de nitidez conceitual dos termos 'global' e 'globalização'. A palavra 'mundial' permite introduzir, com muito mais força do que o termo 'global', a idéia de que, se a economia se mundializou, seria importante construir depressa instituições políticas mundiais capazes de dominar o seu movimento. Ora, isso é o que as forças que atualmente regem os destinos do mundo não querem de jeito nenhum. Entre os países do Grupo dos Sete - EUA, Canadá, Japão, França, Alemanha, Reino Unido, Itália -, os mais fortes julgam ainda poder cavalgar vantajosamente as forças econômicas e financeiras que a liberalização desencadeou, enquanto os demais estão paralisados ao tomarem consciência, por um lado, de sua perda de importância e, por outro, do caminho que vão ter de percorrer para adaptar-se'”. (CHESNAIS, 1996, p. 24).
} 
"flexibilização da organização do trabalho e da produção (polivalência, exteriorização etc.); flexibilização dos tempos de trabalho (diversificação, variabilidade, mobilidade etc.); flexibilização das formas de emprego (redução de proteções contra as garantias de trabalho, alargamento de postos precários); flexibilização do custo salarial direto (posto em causa através da indexação dos salários sobre os preços e de reduções legais) e indireto (reformas de indenização do desemprego)" (FREYSSINET, 1997, p. 3).

A subcontratação, segundo o setor de engenharia da empresa pesquisada, é a única estratégia capaz de assegurar a manutenção das construtoras no mercado, tida então como algo inevitável.

"Hoje eu acredito que a palavra construtora deva acabar, aquela empresa piramidal, verticalizada com diretor, gerente, não sei o que, área de suprimentos, área de financeira, é uma questão de sobrevivência. (Alcides, engenheiro).”

A propósito da estruturação do mercado de trabalho na década de 90, Harvey (1992, p. 145-146) afirma que:

\begin{abstract}
"a subcontratação organizada abre oportunidades para a formação de pequenos negócios e, em alguns casos, permite que sistemas antigos de trabalho doméstico, artesanal, familiar (patriarcal) e paternalistas ('padrinhos', 'patronos' e até estruturas semelhantes à da máfia) revivam e floresçam, mas agora como peças centrais, e não apêndices do sistema produtivo.”
\end{abstract}

A crescente terceirização de etapas do processo construtivo nos canteiros mantidos pela construtora faz com que parte da gerência vislumbre o seguinte cenário para a empresa num futuro não muito distante:

"eu imagino que até eu vou ser acionista desta empresa, eu vou ser um prestador de serviços para a empresa. A empresa num futuro bem próximo vai ser uma marca com prestadores de serviços para esta entidade. (...) Para você entender melhor é o seguinte: uma Nike, ela não faz tênis, ela não faz nada, ela só tem a marca; uma Beneton não faz nada; uma Microsoft também, ela não faz nada, ao contrário, ela mantém uns carinhas pensando para ela lá, só aquele grupo fica pensando lá e ela tem um faturamento astronômico. E esta empresa aqui atuando enquanto empresa-mãe fazendo esses negócios e articulando esses negócios e tudo ${ }^{5}$." (Alcides, engenheiro)

\footnotetext{
5 "O oligopólio, a grande empresa capitalista clássica, multinacional, transnacional, isto é, empresas existentes em centenas de países, empregando centenas de milhares de pessoas, cujas vendas anuais superam o PIB de um grande número de países pequenos, estão se descentralizando, estão ficando menores, porém criando ao seu redor uma rede de pequenas e médias empresas filiadas, subcontratadas, algumas vezes, com posse cruzada de ações. Isso é uma novidade. Dentro disto surge o franqueamento. Estão surgindo grandes redes de empresas, em que o núcleo é comparativamente pequeno. Por exemplo, a Benetton, um caso interessantíssimo, é uma empresa
} 
Passados dois anos da obtenção do depoimento acima, constata-se que certas afirmações ali presentes de fato materializaram-se, como por exemplo, a subcontratação crescente de etapas da obra e a redução de 68,9\% na força de trabalho empregada na produção, enquanto que no setor administrativo a redução atingiu 72,6\%. Por outro lado, o engenheiro que forneceu o depoimento não se tornou acionista ou prestador de serviços da construtora - como pressupunha - e mais, foi demitido juntamente com outros trabalhadores em junho de 2000.

\section{A PRECARIZAÇÃo ABSOLUTA}

Grande parte das análises que priorizam a problematização acerca dos efeitos da terceirização sobre as condições de trabalho indica a crescente precarização e aumento do desemprego que atingem o conjunto dos trabalhadores em diferentes níveis: diminuição dos benefícios sociais; degradação salarial; aumento do desemprego; ausência de equipamento de proteção/falta de segurança/insalubridade; trabalho menos qualificado; trabalho sem registro; desorganização sindical pelo esfacelamento e fragmentação do coletivo de trabalhadores e jornada mais extensa.

O que singulariza a subcontratação nos anos 90 no Brasil é, em primeiro lugar, o seu grau de alcance, por atingir atualmente empresas de edificações de grande porte e que, historicamente, construíram uma trajetória num sentido diverso (como por exemplo, a construtora pesquisada) e, em segundo lugar, situa-se na conjugação nefasta para os trabalhadores, entre subcontratação, desemprego e desregulamentação de direitos trabalhistas.

A redução do número de postos de trabalho, motivada dentre outros fatores pela implementação da terceirização, é a conseqüência mais visível e prejudicial aos trabalhadores.

A situação de desemprego no subsetor apresenta contornos extremamente graves, pois o período de procura por um novo emprego é longo, o desemprego atinge principalmente os trabalhadores desqualificados e ou com idade acima dos 35 anos e estes desempregados 
não possuem qualificação profissional anterior e ou escolarização que lhes possibilite migrar para outros setores produtivos.

Outro aspecto referente ao desemprego diz respeito ao tipo de trabalhador que está sendo cada vez mais desempregado. No caso do subsetor analisado, o desemprego atinge com maior intensidade os trabalhadores não qualificados.

"Infelizmente, o não qualificado cada vez mais vai sobrando no mercado. Então, esse cara que a gente chama de servente, que é aquele que ajuda os outros está saindo do mercado porque as coisas vão sendo mecanizadas. Várias coisas que se faziam na obra, que eram feitas manualmente por um indivíduo vai sendo extinta.” (Luiz Carlos, engenheiro)

A difusão da subcontratação articulada à utilização de novos equipamentos e ferramentas de trabalho, bem como novos materiais, reduzem drasticamente as atividades anteriormente desenvolvidas pelos ajudantes e, por conseguinte, reduz-se o número dos mesmos nos canteiros de obras. Com isso, dá-se o fechamento da porta de entrada para o mercado de trabalho de um enorme contingente de operários migrantes, sem qualificação e analfabetos.

De acordo com o depoimento de um engenheiro, o desemprego do trabalhador sem qualificação é mais dramático:

“você não pode deixar de levar em conta que esse indivíduo não qualificado que está diminuindo, não é só o emprego que ele está perdendo. Esse cara, ele mora na obra e se alimenta nesse local de trabalho. Então, cada vez que ele perde o emprego, ele não perdeu só o emprego, ele perdeu também o teto e a comida, é um indivíduo que não tem onde morar e se alimentar, além de não ter mais salário.” (Moisés, engenheiro)

De acordo com a direção do Sindicato, as construtoras terceirizadas não cumprem a Consolidação das Leis do Trabalho (CLT), chegando ao ponto de sequer pagar os dias trabalhados aos operários.

"Os trabalhadores das subcontratadas trabalham até sem salários, isso nós vemos todo o dia. Tem operário que chega a trabalhar um, dois ou três meses sem receber um tostão. Aí você aciona os órgãos que se dizem competentes para cobrar isso das empresas e aí a coisa se enrola por muito tempo. Nisso, a empresa troca de nome e CGC, pedem falência o dia que quer e o coitado do trabalhador sem receber." (Alcides, diretor do sindicato da construção de Campinas) 
Referindo-se a este tipo de relação, Bresciani (1997, p. 200) ressalta que

\begin{abstract}
"na imensa maioria dos casos, a chamada terceirização à brasileira tem sido apenas mais um expediente para reduzir custos a qualquer preço, em que especialização e qualidade são retórica vazia, e a degradação do trabalho, do trabalhador, e também do produto, se renovam como meios espúrios de competitividade empresarial.”
\end{abstract}

Outra prática crescente a partir da subcontratação é a contratação do trabalhador sem registro em carteira, portanto, sem direitos vinculados ao trabalho. É o crescente desemprego que convence o trabalhador a aceitar esse tipo de emprego.

"Nós vamos encontrar um índice grande de trabalhador sem carteira assinada e esse é o ponto mais explorador que existe. Isso acontece nas terceirizadas, ou dos pequenos construtores, ou dos gatos e isso nós conseguimos detectar principalmente quando tem morte na obra. Aí nós pegamos muitos trabalhadores sem registro e que acabam se acidentando e morrendo, aí é a hora da correria pra registrar o camarada depois de morto, entendeu?" (Alcides, diretor do sindicato da construção de Campinas)

O depoimento acima apresenta passagens que seriam cômicas se não fossem trágicas, como por exemplo, a urgência da empresa subcontratada em legalizar a situação do trabalhador já morto, como se a premissa para a existência formal e legal do trabalhador do canteiro de obras fosse a inexistência.

A adoção da terceirização, segundo a empresa contratante, contribuiu para o aumento da competitividade da mesma, pois possibilitou fundamentalmente a diminuição de custos.

Na ótica de trabalhadores e sindicalistas, a terceirização é sinônimo de precarização das condições de trabalho, pois as condições de trabalho oferecidas pelas construtoras de médio e pequeno porte (terceirizadas) são piores do que as encontradas nas construtoras de grande porte (contratantes). 


\section{CONSIDERAÇÕES FINAIS}

Neste trabalho foram analisados os condicionantes e as implicações decorrentes da implementação do processo de terceirização em uma construtora em São Paulo. A terceirização tem sido utilizada por um número crescente de empresas do subsetor de edificações habitacionais enquanto estratégia de racionalização do trabalho.

A trajetória da construtora pesquisada informa-nos que a busca por maior eficiência através da articulação entre o aumento da produtividade e a minimização de custos viabilizou-se pela escolha de diferentes estratégias de racionalização do processo de trabalho, que procuravam responder a determinadas conjunturas.

Na metade da década de 80, face ao mercado ter se tornado mais competitivo, a empresa procurou investir em qualidade e produtividade. Neste período, o número de trabalhadores à procura de emprego apresenta-se em queda e um dos fatores que contribuíram para esta realidade é o refluxo da imigração. A construtora passa então a ter que disputar força de trabalho com outros setores produtivos. Isto forçou a adoção de medidas que promovessem melhorias das relações de trabalho nos canteiros de obras.

A partir de 1995, o mercado de edificações habitacionais apresenta-se extremamente concorrencial, competitivo e diversificado, o que explica o número crescente de construtoras que encerram suas atividades. Ao mesmo tempo, constata-se o crescimento da oferta de força de trabalho em razão da elevação dos índices de desemprego.

Diante desta nova conjuntura, a construtora substituiu a política de valorização do trabalhador pela terceirização.

O empreendedor terceirizado ou a empresa subcontratada é um trabalhador por conta própria ou até mesmo um empregador sob o controle da empresa contratante. Dessa forma, reelabora-se o conceito de trabalhador coletivo, ampliando-o, pois rompem-se os limites da empresa através da incorporação de outras e outros trabalhadores vinculados a diferentes empresas, no mesmo processo produtivo.

Na realidade, a terceirização propicia diminuição de custos para a empresa contratante porque o valor da remuneração concedida à empresa contratada é inferior ao 
despendido com trabalhadores próprios. A empresa terceirizada, apesar das queixas, mantém um volume de serviços superior ao que detinha anteriormente e obtém redução nos custos de manutenção de seus trabalhadores através da intensificação da precarização das condições de trabalho nos canteiros de obras (burla à legislação trabalhista, pagamento por tarefa, descompromisso com o fornecimento de equipamento e cursos de segurança do trabalho etc.).

Do exposto anteriormente, concluímos que na terceirização, subcontratação, parceria, cooperação, ou seja, qual for a denominação dada a esse tipo de estratégia de flexibilização, a lucratividade auferida pelas empresas resulta da intensificação da exploração da força de trabalho ${ }^{6}$.

A escolarização não propiciou ascensão profissional e tampouco melhoria salarial ao trabalhador do canteiro de obras, o saber ler e escrever alimenta o sonho de um dia poder deixar de trabalhar como pedreiro.

Apesar de aparecerem em algumas falas de trabalhadores vínculos entre educação e trabalho, na visão majoritária dos mesmos a alfabetização é vista como um mecanismo que alterou positivamente suas vidas fora da esfera da produção.

Por último, mas de fundamental importância, é a contribuição da escolarização no sentido de desenvolver a criticidade e a cidadania dos trabalhadores, municiando-os com conhecimentos que lhes possibilitem compreender o mundo em que vivem, formularem críticas e possivelmente participarem de maneira ativa na construção de uma sociedade mais justa e solidária.

A partir do exposto anteriormente, concluímos que apesar de vivermos numa época em que as propostas educacionais enfatizam o uso da Internet, Engenharia Genética, Telemática etc., persiste a justificativa da defesa da universalização do ensino básico de qualidade para um grande segmento da sociedade, pois ao lado da 'modernidade', sobrevive um enorme contingente de pessoas que não sabem sequer ler e escrever e, em uma sociedade letrada, constrangem-se por isso.

\footnotetext{
6 "Antes de tudo, o motivo que impele e o objetivo que determina o processo de produção capitalista é a maior expansão possível do próprio capital, isto é, a maior produção possível de mais valia, portanto, a maior exploração possível da força de trabalho" (MARX, 1982, p. 380).
} 


\section{REFERÊNCIAS}

ABREU, A. R.. P.; SORJ, B. Subcontratação e trabalho a domicílio: a influência de gênero. In: MARTINS, H. S.; RAMALHO, J. R. Terceirização: diversidade e negociação no mundo do trabalho. São Paulo, Hucitec: CEDI/NETS, 1994.

AMADEO, E.; PERO, V. O mercado de trabalho da construção civil e a melhoria da qualidade do emprego. In: DIPES/IPEA. Perspectiva da Economia Brasileira. Rio de Janeiro, 1998.

ARBIX, G. Os descaminhos do governo e a precarização das relações de trabalho. In: CARLEIAL, L. M. F.; VALLE, R. Reestruturação produtiva e mercado de trabalho no Brasil. São Paulo: HUCITEC-ABET, 1997.

BARONE, R. E.; LETELIER, M. E. "Canteiro escola"; uma resposta da indústria da construção no contexto produtivo atual. Educação \& Sociedade, Campinas, n.52, p. 446473, dez. 1995.

BRESCIANI, L. P. Os desejos e o limite: reestruturação industrial e ação sindical no complexo automotivo brasileiro. In: LEITE, M. P. (Org.). O trabalho em movimento: reestruturação produtiva e sindicatos no Brasil. São Paulo: Papirus, 1997.

CARLEIAL, L. M. F. Reestruturação industrial, relação entre firmas e mercado de trabalho; as evidências na indústria eletroeletrônica na região metropolitana de Curitiba. In:

VALLE, R. (Orgs.). Reestruturação produtiva e mercado de trabalho no Brasil. São Paulo: HUCITEC-ABET, 1997.

CARNOY, M.; LEVIN, H. M. Escola e trabalho no estado capitalista. São Paulo, Cortez, 1993.

CASTEL. R. As metamorfoses da questão social: uma crônica do salário. Petrópolis: Vozes, 1998.

ENGUITA, M. F. A face oculta da escola: educação e trabalho no capitalismo. Porto Alegre: Artes Médicas, 1989.

FRIGOTTO, G. Educação, crise do trabalho assalariado e do desenvolvimento: teorias em conflito. In: . (Org.). Educação e crise do trabalho: perspectivas de final de século. Petrópolis: Vozes, 1999.

GENTILI, P. Educar para o desemprego; a desintegração da promessa integradora. In: FRIGOTTO, G. (Org.), Educação e crise do trabalho: perspectivas de final de século. Petrópolis: Vozes, 1999.

GRAMSCI, A. Maquiavel, a política e o Estado moderno. Rio de Janeiro: Civilização Brasileira, 1984. 
HARVEY, D. Condição pós-moderna: uma pesquisa sobre as origens d mudança cultural. São Paulo: Edições Loyola, 1992.

HOLLANDA, F. B.; KEATING, L. A. V. A bordo do Rui Barbosa. São Paulo: Palavra e Imagem, 1981.

MARONI, A. A estratégia da recusa. São Paulo: Brasiliense, 1982.

MARTINS, H. H. T. S. Os dilemas do movimento sindical em face da terceirização. In: .; RAMALHO, J. R. (Orgs.). Terceirização: diversidade e negociação no mundo do trabalho. São Paulo, Hucitec: CEDI/NETS, 1994.

MARX, Karl. O capital: crítica da economia política. São Paulo: Difel, Livro 1, Volume 1, 1982.

MATTOSO, J. E. L. A desordem do trabalho. São Paulo, Scritta, 1996. 